\title{
0 Léxico como Controlador de Mudanças Sonoras
}

\author{
Marco Antônio de Oliveira \\ Universidade Federal de Minas Gerais
}

\section{Abstract}

In this paper I keep the diffusionist assumption that sound changes are better viewed as controlled by the lexicon. Also, I propose here that the lexicon should be taken as the output of grammar. Or, in other words, I propose that the lexicon should be analyzed in terms of the utterances in which it occurs, with all the contextual information that it carries, and not in terms of its virtual characteristics. 


\section{0 - INTRODUÇÃo}

A rias áreas da linguiística não contribuem do mesmo modo para seu avanço - e não vai aqui nenhuma crítica às diferenças encontradas. Por exemplo, me parece que não seria despropositado dizer que em Gramática Gerativa os avanços se fazem muito mais em termos das propostas teóricas do que em termos dos trabalhos empíricos, i.e., é preciso que alguém proponha alguma coisa (geralmente o Chomsky) para que, então, os lingüistas de inclinação gerativista comecem a procurar evidências nas línguas naturais. Assim, de uma certa forma, os dados seriam secundários, o que não significa que eles sejam desprovidos de importância. Aliás, desde o modelo estabelecido no Aspects já se diz que o problema da lingüística não seria o de falta de dados, e sim o de falta de teorias que pudessem dar conta destes dados. Sabemos que os avanços oriundos desta postura foram muito grandes, mas sabemos também que o status de $2^{\mathrm{a}}$ classe atribuído aos dados acabou por conduzir a algumas situações conflituosas, como, por exemplo, aos duelos entre dialetos diferentes quando se tratava de se validar ou invalidar uma proposta de análise, ou mesmo à utilização de "fatos lingüísticos" extremamente suspeitos na construção de uma argumentação qualquer.

Em Sociolingüística ${ }^{1}$, por outro lado, os avanços conseguidos são um pouco mais lentos, exatamente pela direcionalidade entre o teórico e o empírico que os precede. Penso que podemos afirmar que, de modo geral, os avanços se dão do empírico para o teórico, i.e., os pesquisadores passam um grande tempo examinando os fatos encontrados para poder classificá-los e submetê-los a uma análise quantitatica, à qual se segue um enunciado qualitativo que irá, este sim, esclarecer um pouco mais algum aspecto teórico. Há, na literatura, vários exemplos de como o trabalho empírico acabou levando ao esclarecimento de pontos da teoria. Um caso em questão é o trabalho de Labov, Yaeger \& Steiner (1972), que acabou por esclarecer alguns pontos problemáticos do modelo fonológico de 
Chomsky \& Halle (1968), principalmente quanto ao fenômeno da Rotação Vocálica do Inglês. Ainda em fonologia podemos ver como o trabalho muitas vezes maçante da análise de dados nos foi útil no esclarecimento de problemas teóricos interessantes como o da forma das regras, o da estrutura das gramáticas, o do quadro dos traços fonológicos, entre outros. E mesmo fora da fonologia muitas outras áreas se beneficiaram seja dos trabalhos seja das técnicas desenvolvidas dentro da Sociolingüística como, por exemplo, a Análise do Discurso, o Multilingüismo, a Sintaxe, a Pragmática, etc. Ou seja, a Sociolingüística acabou trazendo para a lingüística as preocupações com a linguagem e não apenas as preocupações com a gramática ${ }^{2}$.

Este trabalho fala do léxico e de sua relação com as mudanças sonoras, e tem um tom essencialmente teórico. Muito já se disse sobre o léxico e seu desenvolvimento, ou não, na mudança sonora. Assim, o que eu pretendo fazer aqui não é discutir se o léxico está, ou não, controlando as mudanças sonoras. Os que estão familiarizados com meu trabalho prévio já conhecem minha posição difusionista, posição esta que, até agora, não tive razões para alterar: para mim todas as mudanças sonoras se dão por difusão lexical. Portanto, meu objetivo aqui é o de tentar responder, a partir dos vários trabalhos encontrados na literatura relevante, a seguinte pergunta: quais são as características dos itens lexicais mais propensos a serem atingidos primeiro por uma mudança sonora? Em resumo, em vez de sugerir um novo elenco de traços que possam caracterizar este itens, pretendo sugerir uma nova perspectiva para se considerar as propostas já apresentadas, numa mudança qualitativa da abordagem deste assunto.

\section{1 - O PROBLEMA}

Na discussão estabelecida na literatura entre os modelos Neogramático e Difusionista, um dos problemas centrais é exatamente o do papel do léxico nas mudanças sonoras. Deixando de lado os detalhes analíticos, podemos dizer que a questão não gira em torno de se o léxico conta ou não conta na mudança sonora, ou de se há ou não há alguma influência do contexto fonético na mudança sonora. Embora as análises de inclinação neogramática privilegiem o efeito fonético na implementação de uma mudança sonora, enquanto que as análises de inclinação difusionista privilegiam um controle lexical, não podemos dizer que nenhuma análise séria, independentemente de seu sabor neogramático ou difusionista, ignore as razões do modelo oposto. Por exemplo, por mais neogramática que seja a aná- 
lise, ninguém irá dizer, seriamente, que todas as palavras de uma determinada classe de palavras tenham sido alteradas ao mesmo tempo por uma regra do tipo

$$
\mathrm{X} \Rightarrow \mathrm{Y}
$$

Do mesmo modo, por mais difusionista que seja uma análise, não há como ignorar que certas 'coincidências' fonéticas sejam coincidentes demais para serem ignoradas ${ }^{3}$. Na verdade, a diferença entre as duas abordagens, naquilo que se refere ao papel do léxico nas mudanças sonoras (e não em relação a outros aspectos), se resume na ordenação relativa dos efeitos lexical e fonético. Por exemplo, é interessante observar que os lingüistas de inclinação neogramática resistam à idéia do léxico como controlador primário de uma mudança sonora, mas não à idéia de que, uma vez disparada, a mudança possa ser implementada lexicalmente. Do mesmo modo, nenhum trabalho de inclinação difusionista dirá que o contexto e/ou o efeito fonético não deva(m) ser levado(s) em conta; o que não se aceita é que eles seja uma explicação para uma determinada mudança sonora. Pode-se dizer, portanto, que a diferença básica entre os dois modelos analíticos reside na escolha do controlador principal e do controlador secundário de uma mudança: para o modelo Neogramático temos $1^{\circ}$ ) Fonético $>2^{\circ}$ ) Lexical ${ }^{4}$, enquanto que para o modelo Difusionista temos $1^{\circ}$ ) Lexical $>2^{\circ}$ ) Fonético.

Vamos explicitar, agora, o modelo em que este trabalho se insere. Estou assumindo aqui um modelo idêntico, em essência, àquele proposto por Chen \& Wang (1975): a mola mestra de uma mudança sonora deve ser buscada nos dispositivos fisiológicos e perceptuais dos falantes, enquanto que sua implementação se dá por difusão lexical. O que eu estou chamando de "mola mestra", uma tradução não muito feliz, é aquilo que Chen \& Wang chamaram de 'actuation'. E a questão aqui envolve um problema bastante específico: nas palavras de Chen \& Wang,

“...why does a sound system change the way it does? What, in other words, determines its pattern, direction, and pace?" (pg.264)

A resposta que os autores dão a esta questão, em dois momentos de seu texto, é a seguinte:

"It is at least plausible to suspect that the answer may be found in the physical properties of the speech sounds."(pg. 270)

"As for the actuation aspects of sound change, we have reason to believe that it is mainly the concrete, phonetic properties of speech sounds 
that trigger or allow changes to take place in the sound system, and determine their subsequent development". (pg. 278)

É bom notar que as referências feitas pelos autores às propriedades fonéticas nada têm a ver com o contexto fonético ou algo parecido; elas se referem, isto sim, às propriedades intrínsecas dos sons individuais 5 .

Estou assumindo, portanto, que cada som é uma mudança em potencial, pelas suas propriedades individuais. Estas propriedades são de natureza fisiológica e perceptual ${ }^{6}$. Assim sendo, teremos sons mais propensos do que outros às mudanças (e assunto do qual não nos ocuparemos aqui). Uma vez concretizada uma mudança (e também não nos ocuparemos aqui das razões pelas quais uma mudança potencial acabou se concretizando, mas não outra mudança igualmente potencial), ela se implementará lexicalmente.

Note-se, contudo, que há um espaço entre estas duas fases, a da concretização de uma mudança e a de sua implementação lexical: afinal, por onde foi que esta implementação começou no léxico? Qualquer item poderia ter sido igualmente atingido na primeira leva? É sobre isto que vamos falar a partir de agora.

\section{2 - AS PROPOSTAS}

Muitas têm sido as propostas encontradas na literatura, visando responder à questão de quais são as palavras mais expostas (ou menos expostas) à mudança sonora. Estas propostas vão desde aquelas que procuram determinar o grau de exposição de uma palavra à mudança, em termos puramente não-estruturais, como em Leslau (1969) e Khrishnamurti (1978), até aquelas que procuram combinar fatores estruturais e não-estruturais, como em Fidelholtz (1975) e Phillips (1984). Também no caso do português já foram apresentadas algumas análises que se valeram tanto de condicionamentos estruturais quanto de condicionamentos não-estruturais na tentativa de elucidação de alguns fenômenos de mudança lingüística. Entre estes fenômenos a questão do alçamento das vogais médias pré-tônicas talvez seja o que tenha recebido mais atenção por parte dos pesquisadores. Este caso em particular tem sido analisado tanto como um fenômeno neogramático, como, p. ex., em Bisol (1981), Bortoni, Gomes, Malvar et al. (1990), Callou \& Leite (1986), Maia (1986), entre outros, quanto como um fenômeno puramente difusionista, como em Oliveira (1991), passando por análises 'intermediárias', como Viegas (1987), Bortoni, Gomes 
\& Malvar (1992). Estas análises 'intermediárias' merecem aqui uma explicação a respeito do rótulo que lhes está sendo dado. No caso de Viegas (1987) o rótulo se deve ao fato de a análise apresentar como ponto chave uma regra de natureza neogramática, seguida de comentários de natureza difusionista; no caso de Bortoni, Gomes \& Malvar (1992) o rótulo se deve ao fato de a análise terminar com um enunciado pró neogramático, onde se lê "...apresentamos', neste trabalho, evidências que argumentam a favor da interpretação neogramática do fenômeno estudado"(pg. 27), seguido de um considerável enfraquecimento deste mesmo enunciado, onde se lê “...mas fomentamos a inquietação do leitor, apresentando dados que aparentemente não são explicados por este modelo." (pg. 27). Há, contudo, um ponto em comum entre a análise de Viegas (1987) e a análise de Bortoni, Gomes \& Malvar (1992), que é o fato de se dar precedência explicativa aos fatos fonéticos (mesmo que eles deixem de fora da explicação muitos outros dados). Já no caso de Oliveira (1992) o termo 'intermediário' fica por conta da retomada dos fatos fonéticos numa explicação de natureza difusionista. Como se disse antes, a questão fonética faz parte da análise, mas é precedida pelas considerações lexicais.

Não pretendo retomar aqui a polêmica que envolve a opção por um outro modelo na análise do alçamento das vogais pretônicas. É bem provável que ambas as análises estejam parcialmente corretas e parcialmente equivocadas, à espera de alguém que as possa costurar sem deixar remendos, mais ou menos como nas tentativas levadas a cabo por Labov ((1981) e (1993)) e Harris (1989). Quero selecionar apenas um ponto, que tem sido corretamente criticado nas análises difusionistas pelos lingüistas de inclinação neogramática. Este ponto tem a ver com os traços lexicais que têm sido propostos como favorecedores e/ou inibidores de uma mudança sonora em relação a um item lexical. Assim, numa tentativa de apontar quais seriam os itens lexicais mais propensos a serem atingidos primeiro por uma mudança sonora, Oliveira (1991) caracterizou-os como sendo [+ Comum] (por oposição a [- Comum] ou [+ Próprio]), e como sendo palavras que ocorressem em estilos informais de fala. É evidente que esta

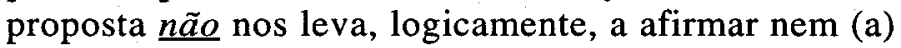

(a)- Nomes [- Comum] não podem apresentar alçamento, nem (b)

(b)- Nomes [+ Comum] sempre apresentarão alçamento.

Assim, Bortoni, Gomes \& Malvar, a partir do levantamento de dados do português arcaico, onde se registram nomes próprios como Subrado, Suariz, Gunçalves, Lianor e Briatriz, concluem que "Os dados levanta- 
dos não confirmam a observação (de Oliveira (1991)) quanto a nomes próprios", muito embora não sejam fornecidos os totais dos nomes $[+\mathrm{Co}-$ mum] e [-Comum], com e sem alçamento. Além deste caso há ainda uma crítica um pouco mais fraca sobre as considerações feitas quanto a Estilo de Fala. Na falta do total de casos considerados e da análise quantitativa que se possa derivar deles, fica a impressão de que a crítica feita é decorrente de uma premissa falsa, (a) ou (b) acima. Contudo, devo dizer que Bortoni, Gomes \& Malvar apresentaram uma crítica relevante, ainda que por razões não muito claras (pelo menos até que possamos examinar os totais dos dados diacrônicos considerados). Afinal, traços como [+/-Comum], [+/-Próprio], [+/-Estilo (in)Formal] são uma propriedade intrínseca dos itens lexicais, ou são 'construídos' nas expressões linguiísticas? Voltaremos a este ponto mais adiante.

Examinaremos agora, rapidamente, algumas das propostas apresentadas na literatura para se apontar as 'primeiras vítimas'de uma mudança, no que se refere aos itens lexicais. Uma das propostas mais comuns é aquela que se utiliza da noção de frequiência para se caracterizar os itens mais expostos a uma mudança. No geral, podemos dizer que estas propostas apontam os itens mais freqüentes como sendo os mais expostos. Um dos primeiros trabalhos nesta linha é o trabalho de Leslau (1969), sobre mudanças em línguas da Etiópia. Nas palavras de Leslau,

"The purpose of the present article is to demonstrate, from evidence in the various Ethiopian languages, how certain phonetic changes that normally occur in the languages affect the frequently used words more than the less frequently used words."(pg. 181)

Note-se que Leslau utiliza uma noção de freqüência relativa, e não de freqüência absoluta, o que me parece ser uma atitude acertada, muito embora Leslau reconheça que sua análise falha por tentar determinar esta frequiência relativa 'de ouvido'8. Afinal, como é que podemos medir a freqüência absoluta de uma palavra? Ainda assim, Fidelholtz (1975) utiliza uma noção de freqüência absoluta para marcar os itens lexicais mais propensos à regra de Redução Vocálica no inglês ${ }^{9}$. No entanto, a análise de Fidelholtz. tem alguns aspectos bastante inusitados. Primeiro, Fidelholtz vincula o efeito da frequiência ao contexto fonético; ou seja, os itens que apresentam redução são bastante freqüentes, mas nem todo item freqüente apresenta redução. Como se vê, sem o contexto fonético adequado - contexto este que é, na verdade, um gradiente - não há redução. Segundo, Fidelholtz abre a possibilidade para a redução vocálica em palavras infreqüentes desde que estas palavras sejam marcadas no léxico com um traço de [Familiaridade], o que me parece muito mais um artifício para se driblar uma exceção. Conforme escreve Fidelholtz. 
"...exceptional infrequent words [eg Astyanax $(<4 / 18 \mathrm{M})]$ which reduce could have a high 'familiarity' number assigned lexically".(pg.207)

Um outro trabalho influente, que considera a freqüencia como sendo um fator determinante na exposição de um item lexical a uma mudança, é o trabalho de Phillips (1984). O mais interessante deste trabalho é que Phillips correlaciona, de maneira diferenciada, a noção de freqüência a mudanças fisiologicamente motivadas e a mudanças não motivadas fisiologicamente: no primeiro caso, as palavras mais freqüentes são atingidas primeiro; no segundo caso, são as palavras menos freqüentes que são atingidas primeiro. Os casos do primeiro tipo envolvem, tipicamente, fenômenos como redução vocálica (cf. Fidelholtz (1975)), assimilações e cancelamentos de shwas (cf. Hooper (1976)), enquanto que os casos do segundo tipo envolvem o que Phillips chama de mudanças que se originam na "conceptual sphere of language, not in the articulatory parameters of the vocal tract" (pp.336-7).$^{10}$ Para outros linguístas, como Shen (1990), a freqüência é uma função do número de falantes que incorporam uma inovação. Assim, nas palavras de Shen, “... for any word, the higher percentage of $u$-speakers (i.e., falantes que não incorporaram uma inovação) indicates a word changes later in the order", e conclui dizendo que "It seems that the factors which determine the order of lexical diffusion still remain an interesting phenomenon to be studied further" (pp.1823). Em resumo, o que se pode dizer é que freqüência tem sido uma categoria explicativa bastante utilizada na tentativa de se determinar as primeiras vítimas lexicais de uma mudança, não obstante as diferenças de tratamento encontradas nas diversas análises.

Outro parâmetro que tem sido propostoé a oposição Erudito (ou Elaborado) X Coloquial. Este parâmetro é sugerido, p.ex. em Oliveira (1992), comentando o comportamento diferenciado das palavras gueixa (sem redução do ditongo [ey]) e deixa/deixei (com redução do ditongo [ey]), onde se lê

"Estes fatos sugerem muito fortemente que itens lexicais marcados como [-Comum] ([+Erudito], [+Especializado] e, muito provavelmente, outros mais são, de fato, mais resistentes à mudança." (pg.37)

Evidências mais recentes do comportamento diferenciado destes parâmetros podem ser vistas no trabalho de Lien (1993) e Wang \& Lien (1993), onde se discute a difusão bidirecional nas mudanças sonoras, envolvendo os estratos literário e coloquial do Chaozhou. Entre outras 
coisas, o travamento silábico nasal do chinês é quase que completamente preservado no estrato literário, sendo quase que completamente perdido no estrato coloquial, após a nasalização da vogal precedente.

O que se pode dizer a partir de propostas como estas é que há uma tentativa de utilização de uma oposição de natureza estilística, que se traduz ora na oposição Formal/Informal, ora na oposição Erudito/Coloquial, ora na oposição Comum/Próprio.

Uma outra versão possível desta oposição é aquela encontrada em Khrishnamurti (1978) que, em sua discussão do deslocamento de apicias em algumas línguas dravídicas, coloca a seguinte questão:

"What kind of lexical items become the early victims of a sound change?" (pg.16)

que ele responde da seguinte maneira:

"The Dravidian data presented here seem to show that the lexical items registering the earliest traces of apical displacement refer to concepts fundamental to the communication and culture of the tribal group, viz. 'two, moon' month, sacrifice, open, enter, etc." (pg. 16)

Mas qual é a relação entre estes aspectos culturais propostos por Khrishnamurti e traços como [+/-Formal], [+/-Erudito], [+/-Comum] e outros? E mais, qual é a relação entre todos eles e frequiência?

\section{3 - UMA ABORDAGEM ALTERNATIVA}

Conforme pudemos ver nesta rápida resenha de alguns trabalhos que procuraram oferecer uma característica significativa para se apontar as primeiras vítimas de uma mudança sonora, tem-se a impressão de que todos têm alguma razão, embora todos não tenham toda a razão. Há algo de importante na noção de freqüência, assim como há algo de verdadeiro na oposição estilística, seja ela traduzida do modo A ou B. Contudo, todas estas propostas têm algo de desconfortável, que se materializa nas exceções encontradas aos traços fundamentais. Ou seja, toda opacidade acaba deixando um gosto amargo na boca do analista. E mais: quando algo não esperado acontece o gosto é ainda mais amargo do que quando algo esperado não acontece. Por exemplo, Fidelholtz ficou muito mais incomodado com 
as palavras infreqüentes que apresentaram redução vocálica do que com as palavras freqüentes que não apresentaram redução vocálica, propondo, inclusive, um traço de exceção para marcar estes casos estranhos no léxico.

O que eu pretendo fazer aqui é sugerir um modo diferente de se abordar estes casos, tornando tanto a oposição estilística quanto o efeito da freqüencia uma função derivada de outra categoria. Esta é apenas uma primeira formulação da proposta,que ainda contém vários pontos que ainda precisam ser mais elaborados. Ainda assim, gostaria de poder comentar estas idéias iniciais. Para tanto, quero retomar, brevemente, alguns pontos já discutidos na literatura.

O primeiro ponto a ser comentado é o da noção de língua. Num texto bastante interessante e ainda inédito Castilho (1993) comenta as várias concepções de teoria lingüística e, conseqüentemente, de língua, agrupandoas em 3 grandes 'famílias'. A primeira 'família', ou Teoria 1, é aquela que concebe a língua como uma atividade mental e, nesta Teoria, língua equivale a cognição. As gramáticas de cunho gerativista, p.ex., se situam nesta macrofamília. A segunda 'família', ou Teoria 2, é aquela que concebe a língua como uma estrutura e, nesta Teoria, língua equivale a código. Nesta macrofamília se situam, p.ex., as gramáticas de cunho estruturalista. A terceira 'família, ou Teoria 3, é aquela que concebe a língua como uma atividade social e, nesta Teoria, língua equivale a enunciação. Nesta macrofamília se situam, p.ex., as gramáticas funcionais, a teoria dos atos da fala, a teoria da variação e mudança e a teoria do discurso.

É interessante observar que a inclusão dos falantes fica consideravelmente diluída à medida que se caminha da Teoria 3 para a Teoria 1 . Não que as Teorias 1 e 2 desconheçam a existência dos falantes ou mesmo a necessidade de se dar conta do chamado desempenho lingüístico. A questão envolve, muito mais, aquilo que se reconhece como sendo o legítimo objeto de preocupação da Lingüística e dos lingüistas. Assim, a Teoria 1 se preocupa muito mais com as estruturas mentais que são responsáveis pela forma das gramáticas, enquanto que a Teoria 2 se preocupa muito mais com a estrutura interna destas gramáticas. Já a Teoria 3 está muito mais interessada no uso que se faz desta gramática nas situações concretas de interação verbal.

Há uma grande discussão, que eu não pretendo reviver aqui, sobre qual seja a melhor teoria lingüística. Afinal, qual delas nos revela o maior número de fatos interessantes sobre as línguas naturais? Na verdade a coisa não é tão simples assim. Há, por detrás de toda esta questão, uma questão 
maior sobre qual seja o objeto de estudo da lingüística: é a linguagem ou são as gramáticas? Seja lá qual for a resposta dada a esta questão, fato é que se faz e se fala muito mais sobre gramática do que sobre linguagem.

Outra questão relacionada a estas opções - e igualmente importante - é a seguinte: precisamos de uma teoria gramatical para podermos explicar o desempenho ou devemos partir dos fatos do desempenho para se construir uma teoria gramatical? Ou trata-se de questões separadas e independentes? Aqui, também, sabemos que não há unanimidade de opiniões. Há de tudo.

Ainda no trabalho de Castilho (1993) encontramos uma referência interessante ao trabalho de Franchi (1976 e 1991). Nas palavras de Castilho

"Em seus diferentes momentos, a Lingüística tenta apreender os elementos constantes dessa definição de seu objeto (i.e., um sistema de signos voluntariamente produzidos). Mas uma forma adequada de apreender os domínios de uma língua natural é admitir, com Franchi 1976 e 1991 que ela se compõe de três sistemas, o sistema semântico, o sistema sintático, $e$ o sistema discursivo, todos eles articulados pelo léxico". (pg.1)

Note-se que, nesta concepção, o léxico tem um papel fundamental, que é o de servir de intermediador entre os outros subsistemas (que, de certa forma, estão no 'mesmo nível', sem que nehum deles comande os outros).

Em trabalho recente Nascimento \& Dillinger propõem, entre outras coisas, e após apresentarem uma série de argumentos, (a)- que as gramáticas sejam vistas como sistemas de representação, e não como sistemas de derivação; e (b)- que as categorias substantivas, tais como N, V, A e $\mathrm{P}$, assim como as categorias que especificam as relações temáticas, tais como Agente, Tema, Paciente, etc, devam ser construídas nas expressões lingüísticas (SDs), não sendo, portanto, categorias primitivas. Estas últimas são, na palavra dos autores,

“...interpreted as referring to relations established at the intersection of the conceptual-intentional and articulatoryperceptual performance systems, as proposed by Chomsky (1992)". (Pg.7)

não sendo, portanto, parte do léxico como categorias primitivas. Neste sentido, a atribuição de traços como N, V, Agente, Paciente, etc., funciona, mutatis mutandis, como a atribuição de certos traços aos morfofonemas (ou aos arquifonemas, nas análises estruturalistas) a partir do contexto. Neste caso específico, estes traços são atribuídos através de marcas de- 
terminadas pela gramática (como, p.ex., FLEX), mas não são primitivos. Aliás, uma das diferenças entre a abordagem que Nascimento e Dillinger fazem do léxico, e aquela feita por Franchi, é exatamente esta: para Franchi os traços em questão são inerentes ao item léxico, enquanto que para Nascimento e Dillinger eles são atribuídos a posteriori.

Num texto razoavelmente recente ${ }^{11}$, Lord \& Zung (1992) tecem uma série de considerações bastante interessantes a respeito do funcionamento do léxico naquilo que os autores chamam de "language praxis". Basicamente, o que estes autores sugerem é uma abordagem do léxico onde se propõe que um traço encoberto, do léxico, designado como convergência morfossemântica (morphosemantic concurrence), seja, ao mesmo tempo, um traço da estrutura lexical quanto um agente da função lexical, servindo para preservar ou alterar o léxico. A convergência morfossemântica não é nada mais, nada menos, que a convergência de forma e sentido, que subjaz às palavras ocorrentes em uma língua. Na medida em que esta convergência morfossemântica se presta a manter um equilíbrio morfossemântico, ela pode promover ou inibir as mudanças. Assim, o léxico não é mais visto nem como um conjunto não-ordenado de morfemas, conforme sugerido em Weinreich (1966), nem como um conjunto não-ordenado de formativos lexicais, conforme sugerido em Chomsky (1965); também não é visto como um sistema estruturado e regulado por regras, à maneira estruturalista, e sim como uma estrutura orgânica, plástica, capaz de se acomodar às demandas dos falantes, capaz de ajustar estrutura e função. Convém observar também que a abordagem de Lord \& Zung se dá "... at a level below that of the lexeme". Ou seja, a abordagem de Lord \& Zung nos coloca fora da concepção de língua como cognição ou código, e nos joga direto na concepção de língua como enunciação. Assim, em vez de se ver os itens lexicais como lexemas, eles são vistos como entidades funcionais, que contêm informações estruturais e não-estruturais; em vez de se considerar os itens lexicais como entidades altamente abstratas, eles são considerados como entidades mais concretas, ou, para colocar de outra forma, como a saída da gramática, e não como a entrada da gramática. Conforme colocam Lord \& Zung,

"The particular advantage of the morphosemantic sub-system (assuming the model proposed here stands up) is that, unlike what is known of other parts of the language system, it is capable of continuous adjustment, through the plasticity and mobililty of its network of MSC"(pg. 369) 
Pudemos ver, então, que há propostas, como a de Nascimento \& Dillinger, no sentido de não se considerar como primitivos os traços substantivos, os temáticos e os funcionais, uma vez que eles podem ser atribuídos a partir das configurações estruturais determinadas pela gramática. Vimos também que há propostas para se considerar o léxico como um sistema plástico, adaptável às necessidades dos falantes ${ }^{12}$, e não como um sistema estruturado de caráter imutável. O que eu quero propor, aqui, é que traços como [+/-Freqüente] e/ou [+/-Formal] sejam, também, traços atribuídos nos itens lexicais a partir das configurações contextuais em que eles se encontram, e não sejam vistos como traços intrínsecos aos itens lexicais individuais.

Consideremos, primeiramente, o traço [Freqüência]. O que eu estou propondo é que este traço não seja atribuído aos itens léxicos nem como traço absoluto, nem como traço relativo. Em vez disto, proponho que o traço [Frequiência] seja atribuído a um item léxico como uma função da frequêencia do contexto onde este item léxico vai ocorrer. Uma vez que a frequiência do contexto que comporta um determinado item léxico não é a mesma de falante para falente, é de se esperar que a marcação de um determinado item léxico como [+ ou - Freqüente] também não seja idêntica de falante para falante, ou de comunidade para comunidade. Assim, podemos preservar a idéia de que o traço [Freqüência] tenha algo a ver com a exposição dos itens lexicais a uma determinada mudança (i.e., itens [+Freqüentes] são mais expostos do que itens [-Freqüentes] sem ter que marcar um determinado item léxico sempre do mesmo modo: ele será marcado como + ou - dependendo da freqüência do contexto onde ele ocorre na 'praxis' linguística dos falantes individuais (ou de grupos de falantes).

Da mesma forma, podemos dizer que o traço [Formalidade] seja derivado da empatia entre o falante e o contexto onde sua fala é produzida. Assim, nenhum item léxico será marcado como [+/- Formal] por natureza ou por comparação: este traço será atribuído a partir da marca a ser atribuída à própria situação de fala (ou, dizendo de outra forma, à empatia entre o falante e a situação de fala).

É evidente que estas propostas apontam para opções específicas. Por exemplo, esta proposta só cabe num modelo onde o objeto de estudo seja a enunciação (e não apenas o código ou a cognição). Além disso, estas propostas só são cabíveis num modelo de gramática onde seja possível incluir nas descrições os aspectos não-estruturais do fenômeno. E, mais importante, estas propostas só são cabíveis numa perspectiva teórica onde haja a possibilidade de ajuste entre forma e sentido (ou, numa versão mais forte, 
onde se possa dizer que forma é sentido, conforme sugerido em Oliveira (1987).

Para finalizar, voltemos à questão inicial deste trabalho. Em que sentido podemos dizer, então, que o léxico seja o controlador das mudanças sonoras? Para responder a esta pergunta não vamos precisar de alterar as hipóteses básicas da posição difusionista, posição esta que já foi bastante bem justificada por uma série de trabalhos que vêm se acumulando desde a década de 60 . Assim, continuaremos dizendo que o léxico controla as mudanças sonoras, abrindo ou fechando as portas à sua implementação, ou acelerando $\mathrm{x}$ retardando a sua implementação. Só que veremos o léxico como um conjunto de traços que são construídos caso a caso, nas situações concretas de interação verbal, e não como algo previamente determinado, que não pode ser alterado. Preservamos, portanto, a visão de plasticidade do léxico, conforme o trabalho de Lord \& Zung, numa imagem bastante feliz desta questão.

\section{4- CONCLUSÃo}

Falando especificamente das mudanças sonoras, diremos que cada som é uma mudança sonora em potencial, ou seja, cada som está livre para variar e, eventualmente, mudar. Não há nada que impeça a troca do campo de dispersão de um som. O que estou querendo dizer aqui é que esta troca, esta inovação, não se dá gratuitamente, mas com uma função definida. $\mathrm{Na}$ verdade esta troca serve para marcar uma nuance a mais no ajuste entre o falante e o contexto. Por exemplo, é bem verdade que os nomes próprios são menos propensos a mudanças, tomados isoladamente. Contudo, se o ajuste entre dois falantes for marcado por um alto grau de empatia, não há nada que impeça que ocorram alterações exatamente nos nomes próprios. Uma evidência disto são os diminutivos de nomes próprios, que indicam familiaridade ou carinho. Assim, para Antônio temos T[u]nico, da mesma forma como temos Bia para Beatriz. Também na linguagem que as mães usam com os filhos de berço encontramos muitos casos deste tipo: p.ex., pé vira 'pizim', preto vira 'pritim', etc. Nestes dois exemplos temos dois casos onde as alterações não eram as esperadas: no $1^{\circ}$ caso temos nomes próprios, e no $2^{\circ}$ temos vogais átonas circunstanciais, i.e., vogais que são. tônicas por natureza e que tiveram seu acento tônico primário alterado em função do acento tônico do sufixo.

Casos como estes, que podem perfeitamente bem ser controlados em termos sincrônicos, podem servir como pontos de apoio para se exami- 
nar os dados diacrônicos, sobre os quais temos um controle muito menor, em conformidade com o Princípio Uniformitário.

Resumindo e concluindo, podemos dizer que (a)- continuamos apostando no léxico como controlador das mudanças sonoras, até prova em contrário, e (b)- entendemos o léxico como um conjunto de traços, ou marcas, construídos nas situações específicas de fala, e não como um conjunto de traços pré-determinados.

\section{NOTAS}

' Estou incluindo neste rótulo geral a dialetologia e a pesquisa sócio-histórica.

${ }^{2}$ Por alguma razão, que ainda não ficou clara para mim, os lingüistas, de modo geral, se preocupam muito mais com as teorias de gramática do que com as teorias de linguagem.

${ }^{3}$ Uma tentativa de se incorporar o efeito fonético numa análise difusionista está em Oliveira (1992).

${ }^{4}$ Muito embora isto seja raramente explicitado.

${ }^{5}$ Uma abordagem parecida pode ser encontrada em Hockett (1965).

${ }^{6}$ Sem mencionar seu engajamento estrutural (cf. Martinet (1955)).

${ }^{7}$ Para uma discussão semelhante, v. Nascimento \& Dillinger (1993).

${ }^{8}$ Segundo Leslau (pg. 181), "There is, of course, the question of the method of determining the relative frequency of use of a particular Ethiopian word. No such statistical data are at our disposal for the Ethiopian languages as are available for other languages. In view of this fact I admit that I relied on intuition in estimating relative frequency, rather than on statistical information".

${ }^{9}$ Fidleholtz se baseia, primordialmente, nos 'actual frequency counts' de Thorndike \& Lorge (1944).

${ }^{10} \mathrm{Um}$ dos argumentos que Phillips tem para demonstrar o caráter conceitual destas mudanças é o fato de elas terem um comportamento parecido com o do nivelamento analógico, que também atinge primeiro as palavras menos freqüentes.

"Agradeço a Maria do Carmo Viegas por ter chamado minha atenção a este texto.

${ }^{12} \mathrm{Na}$ verdade, às necessidades da comunidade. 


\section{REFERÊNCIAS BIBLIOGRÁFIAS}

BISOL, Leda. Harmonia vocálica: uma regra variável. Rio de Janeiro: UFRJ, 1981. Tese de Doutorado, 332p.

BORTONI, Stella, GOMES, C., MALVAR, E. et.al. "Um estudo preliminar do /e/ pretônico". In: Encontro Nacional da ANPOLL, 5, 1990. Recife. BORTONI, Stella, GOMES, C. \& MALVAR, E.: "Variação das vogais médias pretônicas no português de Brasília: um fenômeno neogramático ou de difusão lexical?"' In: Revista de Estudos da Linguagem, $\mathrm{n}^{\circ} 1, \mathrm{Fa}-$ culdade de Letras da UFMG, 1992, pp. 9-30.

CALLOU, Dinah \& Y. LEITE: "Variação das vogais pretônicas". In: Simpósio Diversidade Lingüística no Brasil, 1, 1986; Salvador, Atas... pp. 157-169.

CASTILHO, Ataliba T. de: "Teorias da linguagem e lingüística". Texto inédito, $1993,19 \mathrm{p}$.

CHEN, M \& W.S.Y. WANG: "Sound change: actuation and implementation". Language, v. 51, n.2, pp.255- 281, 1975.

CHOMSKY, Noam.: Aspects of the theory of syntax. Cambridge, Mass.: MIT Press, 1965.

Harper and Row, 1968.

\& M.HALLE: The sound pattern of English. New York:

FIDELHOLTZ, James. "Word frequency and vowel reduction in English". CLS 11, pp. 200-213, 1975.

FRANCHI, Carlos. Hipóteses para uma teoria funcional da linguagem. Campinas, UNICAMP, Tesè de Doutorado, 2 vols. 1976.

IEL-UNICAMP.

"Hipóteses para uma E-língua". Conferência proferida no

HARRIS, John: "Towards a lexical analysis of sound change in progress. Journal of Linguistics 25, pp. 35-56, 1989.

HOPPER, Joan: "Word frequency in lexical diffusion and the source of morphophonological change. Current progress in historical linguistics, William M. Christie Jr. (ed.), Amsterdam: North-Holland, pp. 95-105, 1976.

KHRISHNAMURTI, B. "Areal and lexical diffusion of sound change". Language, v. 54, n. 1, pp. 1-20, 1978. 
LABOV, William: "Resolving the neogrammarian controversy". Language, v. 57, n. 2, pp.267-308, 1981.

: "A proposed resolution of the regularity question". Principles of Linguistic Change, vol 1: Internal Factors, Chapter 18 (43 p.), Basil Blackwell (in press), 1993.

, M.YAEGER, \& R. STEINER: A quantitative study of sound change in progress. Philadelphia: US Regional Survey, 2 Vol., 1972.

LESLAU, Wolf. "Frequency as determinant of linguistic change in the Ethiopian languages". Word 25, pp. 180-89, 1969.

LIEN, Chinfa: "Bidirectional diffusion in sound change revisited". Journal of Chinese Linguistics, vol 21, n. 2, pp. 254-275, 1993.

LORD, Robert \& Chang Tsong ZUNG: "How does the lexicon work?". Word, vol. 43, n.3. pp. 349-373, 1992.

MAIA, Vera, L.M.: "Vogais pretônicas médias na fala de Natal". Estudos lingüísticos literários 5, n.1, Salvador, pp. 209-225, 1986.

MARTINET, André. Èconomie des changements phonétiques. Berne: Francke, (1955)

NASCIMENTO,M. \& M.L. DILLINGER: "The lexicon and the form of a minimalist grammar: evidence from Brazilian Portuguese". Texto inédito, 40 pp. 1993.

OLIVEIRA, Marco A. de: "Variável lingüística: conceituação, problemas de descrição gramatical e implicações para a contrução de uma teoria gramatical". D.E.L.T.A., vol. 3, n. 1, São Paulo, pp. 19-34, 1987.

: "The neogrammarian controversy revisited". International Journal of the Sociology of Language. Berlin, vol. 89, pp. 93-105, 1991. : "Aspectos da difusão lexical". Revista de Estudos da Linguagem. Faculdade de Letras da UFMG, Belo Horizonte, pp. 31-41, 1992. PHILLIPS, B.S.: "Word frequency and the actuation of sound change". Language.vol. 60, n. 2, pp. 320-342, 1984.

SHEN, Zhongwei: "Lexical diffusion: a populational perspective and a mathematical model". Journal of Chinese linguistics, vol. 18, pp. 159-201, 1990.

VIEGAS, M.C.: Alçamento de vogais médias pretônicas: uma abordagem sociolingüística". Dissertação de Mestrado, FALE/UFMG, Belo Horizonte, 1987. 
WANG, W.S.Y. \& Chinfa LIEN: "Bidirectional diffusion in sound change". Historical Linguistics, Charles Jones (ed.), Cap. 12, London: Longmans, pp. 345-400, 1993.

WEINREICH, Uriel: "Explorations in semantic theory". Current trends in linguistics. Ed. Thomas A. Sebeok, The Hague: Mouton, pp. 395-478, 1966. 